\title{
PENGEMBANGAN VIRTUAL LABORATORY TERMODINAMIKA DI SEKOLAH MENENGAH ATAS
}

\author{
Elce Purwandari \\ Institut Agama Islam Al Azhaar Lubuklinggau \\ purwandari.elce@gmail.com
}

Submit, 30-07-2019 Accepted, 28-08-2019 Publish,28-08-2019

\begin{abstract}
: this study aims to produce virtual laboratory thermodinamic that is valid, practical, and effective used in learning physics at SMAN 2 Palembang. Using development research methods the Hannafin and Peck model which consist of three phases, namely analysis phases, design phases, and development and implementation phases. At the development and implementation phases of evaluation method of Tessmer. Virtual laboratory are declared valid after an evaluation by an expert review. Virtual laboratory is then evaluated by students in the phase of one-to-one and small group and is declared very practical to use. The results of data analysis of Learning motivation of the students increase an average from 0,69 become 0,8, learning outcomes of the students increase an averag from 43,13 become 76,13. The results of $\mathrm{N}$-gain analysis show an 0,58 with a medium category. It was concluded that virtual laboratory thermodynamic it has been developed was proven to be valid, practical, and effective. This shows that virtual laboratory thermodynamic can be developed, practical to used, and increases motivation and student cognitive learning outcomes.
\end{abstract}

Keywords: Virtual Laboratory, Thermodynamics, Valid, Practical, and Effective

Abstrak: penelitian ini bertujuan untuk menghasilkan Virtual laboratory termodinamika yang valid, praktis, dan efektif digunakan dalam pembelajaran Fisika di SMAN 2 Palembang. Menggunakan metode penelitian pengembangan model Hannafin and Peck yang terdiri dari 3 fase yaitu analisis, desain, dan pengembangan dan implementasi. Pada fase pengembangan dan implementasi dilakukan evaluasi dengan metode Tessmer. Virtual laboratory dinyatakan valid setelah dilakukan evaluasi oleh expert review. Virtual laboratory di evaluasi oleh peserta didik pada tahap one-to-one dan small group dan dinyatakan sangat praktis digunakan. Hasil analisis data motivasi belajar peserta didik meningkat secara rerata dari 0,69 menjadi 0,81 dan hasil belajar peserta didik meningkat secara rerata 43,13 dan hasil post-test diperoleh menjadi 76,13. Hasil analisis $N$-gain didapat sebesar 0,58 dengan kategori sedang. Disimpulkan bahwa virtual laboratory termodinamika yang telah dikembangkan terbukti valid, praktis, dan efektif. Hal ini menunjukkan bahwa Virtual laboratory termodinamika dapat dikembangkan, praktis digunakan, dan meningkatkan motivasi dan hasil belajar kognitif peserta didik.

Kata Kunci:Virtual Laboratory, Termodinamika, valid, Praktis, dan Efektif

\section{PENDAHULUAN}

Pendidikan memegang peranan penting dalam menciptakan masyarakat yang cerdas baik secara intelektual, emosional maupun spiritual. Berbagai macam pendekatan instruksional yang dikemas dalam bentuk program pembelajaran berbasis komputer atau Computer Based Instruction (CBI). CBI dimanfaatkan pendidik dalam proses pembelajaran dalam menyampaikan pesan kepada peserta didik untuk menghindari verbalistik yang masih mungkin terjadi jika menggunakan alat bantu visual saja. Penggunaan alat bantu visual tidak mampu memberikan pengalaman langsung kepada pendidik dalam mengkonkritkan suatu pesan yang akan disampaikan oleh pendidik, karena peserta didik lebih banyak mendengarkan penjelasan dari guru, sehingga pesan yang disampaikan tentu saja menjadi semakin abstrak. Dale menyatakan bahwa kemampuan daya serap melalui indera pendengaran yang dimiliki terbatas hanya 20\% (Iskandar, 2009). Oleh karena itu, CBI dimanfaatkan dalam proses pembelajaran untuk mengkonkritkan pesan yang bersifat abstrak.

CBI dapat berupa video pembelajaran, animasi yang menarik, 
dan simulasi yang dapat dilakukan langsung oleh peserta didik sebagai pengguna sehingga diharapkan pembelajaran menjadi lebih efektif dan menyenangkan. Pembelajaran yang seperti ini dimaksudkan agar peserta didik menjadi lebih termotivasi dalam belajar sehingga dapat meningkatkan hasil belajar.

Fisika merupakan salah satu mata pelajaran yang ada dalam struktur kurikulum di Sekolah Menengah Atas (SMA). fisika membutuhkan hands-on (kerja yang dilakukan melalui praktikum) dan minds-on (berpikir). Oleh sebab itu, untuk menguasai Ilmu Pengetahuan Alam (IPA), khususnya fisika tidak cukup hanya diperoleh dengan cara belajar dari buku atau sekedar mendengarkan penjelasan dari pihak lain, akan tetapi diperlukan suatu kegiatan pembelajaran yang melibatkan adanya suatu kegiatan proses untuk menghasilkan produk tersebut.

Kegiatan laboratorium dalam pembelajaran fisika dapat digunakanuntuk menunjukkan peristiwa atau gejala fisika sehingga peserta didik dapat terlibat langsung dalam melaksanakanpengamatan tersebut. Dalam melaksanakan kegiatan laboratorium, unit sarana kegiatan fisika yang dibutuhkan paling sedikit seperempat jumlah peserta didik dalam satu kelas. Bila kegiatan laboratorium dilaksanakan secara kelompok, dengan anggota kelompok empat peserta didik. Jadi, jika dalam satu kelas ada empat puluh (40) peserta didik, maka sekurang-kurangnya ada sepuluh (10) set peralatan (Sutarto, 2003).

Hasil observasi di Sekolah Menengah Atas Negeri (SMAN) 2 Palembang, bahwa peserta didik sulit memahami materi termodinamika yang merupakan sains eksperimental sehingga peserta didik membutuhkan pembelajaran melalui kegiatan praktikum. Laboratorium fisika SMAN 2 Palembang sudah memiliki alat praktikum antara lain: Komponen Instrumen Terpadu (KIT) Mekanika, KIT Optik, dan KIT Listrik sedangkan KIT untuk percobaan pada materi termodinamika tidak tersedia.

Penelitian pendahuluan yang telah dilakukan dengan menyebarkan angket kepada peserta didik di kelas XI IPA 1, didapatkan data bahwa media pembelajaran yang digunakan berupa buku teks fisika dan LKS belum sepenuhnya berpengaruh terhadap motivasi belajar dan hasil belajar peserta didik.

Peserta didik membutuhkan pembelajaran melalui kegiatan praktikum yang dapat dilakukan secara mandiri dan dilakukan berulang kali untuk membangun dan mengembangkan pengetahuan dan keterampilannya dengan menggunakan komputer, sehingga peserta didik dapat mengetahui konsep termodinamika, dapat melakukan simulasi lengkap dengan pembahasannya secara individu. Diakhir kegiatan pembelajaran, peserta didik mengharapkan adanya evaluasi yang berisikan soal-soal dan langsung tercantum nilai hasil evaluasi yang diperoleh lengkap dengan pembahasan sehingga akan dapat meningkatkan motivasi belajar dan hasil belajar pada materi termodinamika.

Termodinamika merupakan merupakan sains eksperimental sehingga konsep-konsep termodinamika harus diperoleh melalui eksperimen. Eksperimen seharusnya dilakukan secara nyata melalui pengalaman langsung agar peserta didik dapat membangun pengetahuannya sendiri, namun peralatan laboratorium untuk materi termodinamika tidak tersedia. Untuk mewujudkan kebutuhan peserta didik dan mengatasi tuntutan materi termodinamika yang bersifat sains 
eksperimental makadikembangkan multimedia pembelajaran yang berupa virtual laboratory (laboratorium virtual) yang bersifat interaktif sehingga akan terjadi interaksi antara peserta didik dan sumber belajar (virtual laboratory) dalam proses pembelajaran. Pembelajaran menggunakan virtual laboratory dapat dilakukan dimana saja, dan kapan saja oleh peserta didik sehingga pembelajaran tidak terbatas pada ruang laboratorium. Pemilihan Virtual laboratory untuk materi termodinamika dikarenakan media pembelajaran ini belum pernah ada di SMAN 2 Palembang.

\section{LANDASAN TEORI}

Virtual Laboratory

Virtual Lab menyajikan model interaktif, alat-alat pembelajaran eksploratif untuk mendukung kuliah, hands-on training, pekerjaan rumah dan penelitian. Virtual laboratory merupakan laboratorium yang berupa software dengan memanfaatkan komputer sebagai media untuk mengaplikasikannya. Program yang digunakan menggunakan adobe flash CS6. Adobe Flash CS6 merupakan versi baru dari Adobe Flash CS5. Adobe Flash Sebelumnya telah memiliki 14 versi.

Motivasi Belajar

Motivasi sering dipandang sebagai faktor yang cukup dominan diantara dari berbagai faktor yang mempengaruhi belajar. Mc Donald merumuskan bahwa motivation is an energy change within the person characterized by affective arousal and anticipatory goal reaction, yang diartikan bahwa motivasi suatu perubahan energi dalam diri (pribadi) seseorang yang ditandai dengan timbulnya perasaan dan reaksi untuk mencapai tujuan (Hamalik, 2010). Motivasi belajar dapat timbul karena faktor instrinsik dan faktor ekstrinsik (Iskandar, 2009). Motivasi yang timbul karena faktor intrinsik atau faktor dalam diri peserta didik disebabkan oleh dorongan atau keinginan akan kebutuhan belajar, harapan, dan citacita, sedangkan motivasi karena faktor ekstrinsik atau faktor dari luar diri peserta didik disebabkan karena adanya penghargaan, lingkungan belajar yang menyenangkan, dan kegiatan belajar yang menarik (Iskandar, 2009).

Motivasi belajar dalam penelitian ini dikembangkan dari teori motivasi model ARCS (attention, relevance, confidence, dan satisfaction) yang dikembangkan oleh Keller (2000).

\section{Hasil Belajar}

Hasil belajar merupakan keberhasilan peserta didik dalam mencapai tujuan pembelajaran yang telah ditentukan. Dalam proses pembelajaran untuk mengetahui keberhasilan peserta didik dalam mencapai tujuan pembelajaran maka dilakukan penilaian hasil belajar. Hasil belajar adalah kemampuan-kemampuan yang dimiliki peserta didik setelah ia menerima pengalaman belajarnya (Sudjana, 2010). Hasil belajar biasanya dapat diketahui melalui kegiatan evaluasi yang bertujuan untuk mendapatkan data pembuktian yang akan menunjukkan sampai dimana tingkat kemampuan dan keberhasilan peserta didik dalam pencapaian tujuan pembelajaran (Purwanto, 2004).

Hasil belajar peserta didik dinilai berdasarkan klasifikasi dari Bloom. Bloom secara garis besar membaginya menjadi tiga ranah, yakni ranah kognitif, ranah afektif, dan ranah psikomotorik (Sudjana, 2010).Nilai dari hasil belajar peserta didik dapat dinyatakan dalam bentuk angka, huruf, maupun kata-kata baik, sedang, dan buruk. 


\section{METODE PENELITIAN}

Penelitian ini bertujuan untuk mengembangkan Virtual laboratory termodinamika, oleh sebab itu penelitian ini merupakan penelitian pengembangan yang menggunakan model pengembangan Hannafin and Peck. Model pengembangan Hannafin and Peck adalah sebuah model pengembangan yang berorientasi pada produk. Model pengembangan ini terdiri dari tiga fase, yaitu: 1) fase analisis; 2) fase desain; dan 3) fase pengembangan dan implementasi (Wiyani, 2013).

Subjek penelitian adalah siswa kelas XI IPA 1 SMAN 2 Palembang pada semester genap tahun ajaran 2014/2015. Untuk mendapatkan data yang dibutuhkan dalam penelitian ini dilakukan pengumpulan data melalui wawancara, dokumentasi, walkthrough, angket, observasi dan tes.

\section{HASIL PENELITIAN}

Fase analisis (analyze).

Kegiatan yang dilakukan pada fase ini yakni sebagai berikut.

\section{Wawancara}

Wawancara dilakukan dengan guru fisika kelas XI SMAN 2 Palembang diperoleh informasi bahwa materi termodinamika terkategori sulit untuk dipelajari peserta didik sehingga ketercapaian kompetensi pada materi ini masih berada di bawah KKM. Proses pembelajaran di kelas hanya menggunakan media cetak berupa buku teks fisika, dan Lembar Kerja Siswa (LKS) sedangkan peralatan pendukung yang digunakan hanya white board dan spidol.Metode yang telah digunakan antara lain: ceramah, latihan dan penugasan.

\section{Mengidentifikasi kebutuhan peserta didik}

Penelitian pendahuluan yang telah dilakukan dengan menyebarkan angket menjelaskan bahwa peserta didik membutuhkan pembelajaran melalui kegiatan praktikum yang dapat dilakukan secara mandiri dan dilakukan berulang kali untuk membangun dan mengembangkan pengetahuan dan keterampilannya dengan menggunakan komputer, sehingga peserta didik dapat mengetahui konsep termodinamika, dapat melakukan simulasi lengkap dengan pembahasannya secara individu mengenai terjadinya proses isotermik, isobarik, isokhorik, dan adiabatik. Diakhir kegiatan pembelajaran, peserta didik mengharapkan adanya evaluasi yang berisikan soal-soal dan langsung tercantum nilai hasil evaluasi yang diperoleh lengkap dengan pembahasan.

\section{Mengidentifikasi perilaku dan karakteristik peserta didik} Berdasarkan chart of learner characteristics (Alessi and Trollip, 2000), peserta didik dengan umur 16 tahun pada tingkat pendidikan kelas XI SMA memiliki tingkatan motivasi yang berbeda. Pada materi termodinamika, peserta didik memiliki pengetahuan dan kemampuan prasyarat yang baik. Kemampuan mengetik tiap peserta didik juga dikatakan baik, hal ini terlihat dari $100 \%$ peserta didik yang kemampuan akademiknya lemah mengetik dengan menggunakan 2-9 jari, $100 \%$ peserta didik yang kemampuan akademiknya sedang mengetik dengan menggunakan 2-9 jari, dan $100 \%$ yang kemampuan akademiknya kuat mengetik dengan menggunakan 2-9 jari.

Virtual laboratory tidak menuntut peserta didik untuk dapat mengetik dengan sangat baik, karena pada produk ini peserta didik dapat mengoperasikannya dengan cara melakukan klik. Setiap peserta didik tidak merasa asing lagi dengan komputer. Peserta didik terbiasa mengakses komputer dan web. Hal ini 
terlihat dari $50 \%$ peserta didik dengan kemampuan akademik lemah dapat mengakses komputer satu minggu tiga (3) kali dan mengakses web satu minggu tiga (3) kali sebanyak $44 \%$ peserta didik, $45 \%$ peserta didik dengan kemampuan akademik sedang dapat mengakses komputer satu minggu sekali dan satu minggu tiga (3) kali mengakses web sebanyak $55 \%$ peserta didik, dan $82 \%$ peserta didik dengan kemampuan akademik kuat dapat mengakses komputer satu minggu tiga (3) kali dan satu minggu tiga (3) kali mengakses web sebanyak $82 \%$ peserta didik. Selain itu $67 \%$ peserta didik dengan kemampuan akademik lemah dapat menemukan informasi dari web membutuhkan waktu 1-5 menit, 55\% peserta didik dengan kemampuan akademik sedang dapat menemukan informasi dari web membutuhkan waktu 1-5 menit, dan sebanyak $64 \%$ peserta didik dengan kemampuan akademik kuat dapat menemukan informasi dari web membutuhkan waktu 1-5 menit.

\section{Mengidentifikasi tujuan Virtual laboratory yang dikembangkan \\ Pencapaian rata-rata hasil} belajar peserta didik pada semester ganjil tahun ajaran 2014/2015 sebesar 71,83 dengan KKM 75. Dalam proses pembelajarannya, tenaga pendidik hanya memanfaatkan media cetak berupa buku teks fisika, dan LKS. Permasalahan ini dicoba dipecahkan dengan mengembangkan Virtual laboratory.

Menetapkan objek pada Virtual laboratory yang dikembangkan

Objek materi termodinamika ini didasarkan pada hasil observasi yang telah dilakukanyaitu atas pencapaian hasil belajar peserta didik yang belum optimal.

\section{Melakukan evaluasi dan revisi terhadap analisis yang dibuat}

Setiap tahap yang dilakukan dalam fase ini dievaluasi dan direvisi sesuai dengan kajian literatur dan pertimbangan ahli. Evaluasi dengan mengumpulkan data dan melakukan kajian pustaka melalui buku referensi mengenai pemrograman adobe flash CS6. Selain itu referensi mengenai Virtual laboratory mengacu pada jurnal yang berkaitan dengan Virtual laboratory. Revisi yang dilakukan dalam menganalisis data pada fase analisis kebutuhan dan analisis karakteristik peserta didik disesuaikan dengan kajian teori. Setelah semua kepentingan diidentifikasi, tahap selanjutnya adalah fase perancangan (design).

\section{Fase desain}

Kegiatan yang dilakukan pada fase ini yakni sebagai berikut.

\section{Merancang materi pada Virtual laboratory} pembelajaran memformulasikan Garis Besar Isi Media (GBIM) dan peta materi. Pada silabus pembelajaran fisika terdapat materi termodinamika dengan Kompetensi Inti (KI), Kompetensi Dasar (KD), dan kemudian dijabarkan dengan beberapa indikator yang mencerminkan tujuan pembelajaran. Pada penelitian ini, materi yang dikembangkan adalah usaha dalam proses termodinamika, hukum I termodinamika, dan mesin carnot. Berdasarkan analisis kebutuhan materi, materi usaha dalam proses termodinamika, hukum I termodinamika, dan mesin carnot.

Kegiatan selanjutnya adalah memformulasikan GBIM, Virtual laboratory memanfaatkan media yang bervariasi, yaitu teks, gambar, suara (audio), animasi, dan video. 
Pemanfaatan media yang bervariasi ini disesuaikan dengan karakteristik dari pokok materi.

Membuat paper-based, yakni membuat desain berupa flowchart dan naskah (storyboard)

Pembuatan dokumen storyboard mencakup gambaran produk Virtual laboratory. Pada tahap ini menghasilkan Rencana Pelaksanaan Pembelajaran (RPP) sebagai panduan untuk melaksanakan pembelajaran. Selanjutnya menghasilkan dokumen flowchart dan storyboard yang mencakup gambaran produk Virtual laboratory.

Pembuatan flowchart dalam Virtual laboratory, yang dimulai dari halaman pembuka, halaman judul, menu utama pada multimedia, isi materi yang dipelajari, penilaian, dan penutup. Flowchart Virtual laboratory materi termodinamika. Tahap selanjutnya setelah membuat flowchart adalah membuat contoh storyboard.

Melakukan evaluasi dan revisi terhadap desain yang telah dibuat

Evaluasi dilakukan dengan membuat indikator-indikator pada RPP yang sesuai berdasarkan KD. Selanjutnya mengkaji tujuan pembelajaran sesuai dengan indikator pembelajaran.materi yang disampaiakan sesuai dengan KD. Setelah mengkaji tujuan pembelajaran, kemudian mengkaji flowchart dan storyboard yang disesuaikan dengan tujuan pembelajaran. Revisi dilakukan dengan merevisi RPP, flowchart, dan storyboard yang disesuaikan dengan silabus.

Fase Pengembangan dan Implementasi

Kegiatan yang dilakukan pada fase ini yakni sebagai berikut.

Mengembangkan Virtual laboratory dengan menggunakan program Adobe
Flash CS6 berdasarkan flowchart yang telah dibuat.

Pembuatan Virtual laboratory dengan menggunakan program Adobe Flash CS6 dibuat oleh peneliti dan programmer. Proses pendesainan dilakukan dengan berdasarkan pada flowchart dan storyboard yang telah dibuat.

Melakukan evaluasi dan revisi terhadap proses pembuatan Virtual laboratory

Selama proses pendesainan Virtual laboratory dilakukan evaluasi dan revisi sehingga produk telah sesuai dengan silabus, RPP, flowchart, dan storyboard.

\section{Self Evaluation}

Tahap dilakukan untuk memperbaiki kekurangan dan kekeliruan yang terjadi pada saat proses produksi. Produk Virtual laboratory yang telah dikembangkan dan telah dilakukan evaluasi diri ini disebut dengan prototype pertama.

Review ahli (expert review) dan Evaluasi satu-satu (one-to-one evaluation)

\section{Reviu ahli (expert review)}

Hasil desain prototype pertama selanjutnya divalidasi oleh ahli (tahap expert review). Rekapitulasi hasil validasi yang dilakukan oleh para ahli dapat dilihat pada Tabel 1 berikut.

Tabel 1.Rekapitulasi hasilreviu ahli (expert

\begin{tabular}{ccccc}
\multicolumn{5}{c}{ review) } \\
No & Bid. Ahli & Validator & $\begin{array}{c}\text { Skor } \\
\text { Validasi }\end{array}$ & Kategori \\
\hline 1 & & & 3,41 & Cukup \\
& Ahli & AFO & & Valid \\
& Media & & & Sangat \\
& Pembelaja & SU & 4,23 & Valid \\
& ran & & & Valid \\
& & HA & 3,86 & Sangat \\
2 & Ahli & MD & 4,37 & Valid \\
& Materi & & & Valid \\
& Pembelaja & EY & 4,13 & Valid \\
& ran & YU & 4,09 & Sangat \\
3 & Ahli & AH & 4,26 & Valid
\end{tabular}




\begin{tabular}{cccc}
$\begin{array}{c}\text { Pembelaja } \\
\text { ran }\end{array}$ & EH & 4,26 & $\begin{array}{c}\text { Sangat } \\
\text { Valid }\end{array}$ \\
\hline Rata-rata & & 4,08 & Valid \\
\hline
\end{tabular}

Berdasarkan pendapat dari reviu ahli disimpulkan bahwa Virtual laboratory materi termodinamika yang telah dikembangkan telah memenuhi aspek validitas diperoleh rerata sebesar 4,08 dengan kategori valid.

\section{Evaluasi satu-satu (one-to-one evaluation)}

Prototype pertama juga dilakukan evaluasi satu-satu (one-toone evaluation) terhadap tiga orang peserta didik dengan kemampuan tinggi, sedang, dan rendah.Hasil one to one evaluation dapat dilihat pada Tabel 2 berikut.

Tabel 2. Hasil Rekapitulasi Angket Peserta Didik Pada Tahap Rekapitulasi Oneto-one Evaluation

\begin{tabular}{llll}
\hline No & $\begin{array}{l}\text { Peserta } \\
\text { Didik }\end{array}$ & $\begin{array}{l}\text { Skor } \\
\text { Kepraktisan }\end{array}$ & Kategori \\
\hline 1 & STA & 4,40 & Sangat Praktis \\
2 & AF & 4,20 & Praktis \\
3 & DH & 4,08 & Praktis \\
\hline & Rata-rata & 4,23 & Sangat Praktis \\
\hline
\end{tabular}

\begin{abstract}
Berdasaran pada kedua tahap evaluasi tersebut maka dapat disimpulkan bahwa prototype pertama yang telah direvisi menjadi prototype kedua selanjutnya digunankan pada tahap berikutnya yaitu tahap evaluasi kelompok kecil (small group evaluation).
\end{abstract}

Evaluasi kelompok kecil (small group evaluation)

Small group evaluation dilakukan oleh 8 (Delapan) orang peserta didik yang dipilih mewakili kelompok peserta didik dengan kemampuan akademik rendah yaitu; MF, MDS, dan IN, mewakili kelompok peserta didik dengan kemampuan akademik sedang yaitu; BES, dan IS, mewakili kelompok peserta didik dengan kemampuan akademik tinggi yaitu; RA, KIF, dan MDR. Tujuan dari melakukan evaluasi kelompok kecil adalah untuk melihat kepraktisan Virtual laboratory yang dikembangkan sebelum dilakukan uji coba pada subjek penelitian di kelas yang sebenarnya.

Hasil penilaian dari 8 (Delapan) peserta didik dalam tahapsmall group evaluation dapat dilihat pada 3 berikut.

Tabel 3. Hasil Rekapitulasi Angket Peserta Didik Pada Tahap Rekapitulasi Small Group Evaluation

\begin{tabular}{llll}
\hline No & $\begin{array}{l}\text { Peserta } \\
\text { Didik }\end{array}$ & $\begin{array}{l}\text { Skor } \\
\text { Kepraktisan }\end{array}$ & Kategori \\
\hline 1 & RA & 4,40 & Sangat Praktis \\
2 & KIF & 4,48 & Sangat Praktis \\
3 & MDR & 4,52 & Sangat Praktis \\
4 & BES & 4,44 & Sangat Praktis \\
5 & IS & 4,44 & Sangat Praktis \\
6 & MF & 4,56 & Sangat Praktis \\
7 & MDS & 4,44 & Sangat Praktis \\
8 & IN & 4,48 & Sangat Praktis \\
\hline \multicolumn{2}{c}{ Rata-rata } & 4,47 & Sangat Praktis \\
\hline
\end{tabular}

Uji coba di kelas sebenarnya (field test)

Hasil uji coba sebenarnya di kelas XI IPA 1 SMAN 2 Palembang menunjukkan bahwa prototype ketiga memiliki efektifitas terhadap motivasi belajar dan hasil belajar kognitif peserta didik. Rerata hasil angket motivasi dapat dilihat pada gambar 1 berikut.

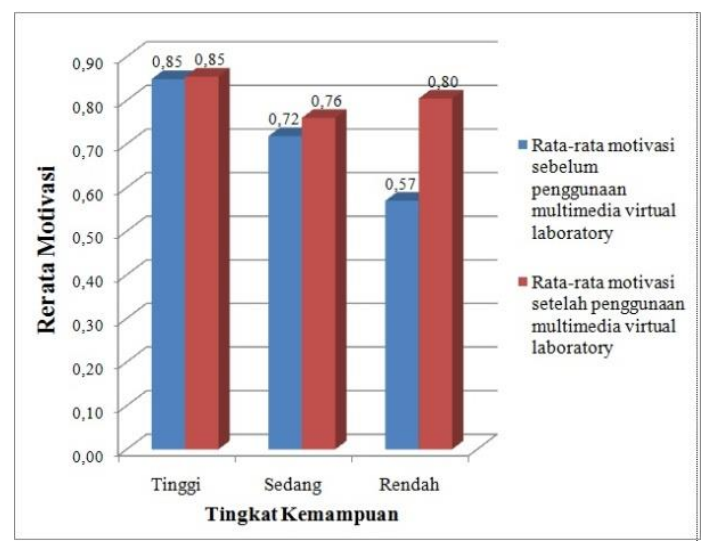

Gambar 1. Rerata Motivasi Belajar Peserta Didik Kelas XI IPA 1 Sebelum dan Setelah Menggunakan Virtual laboratory Dalam Pembelajarannya

Rekapitulasi perbandingan motivasi belajar peserta didik kelas XI 
IPA 1 yang pembelajarannya sebelum menggunakan Virtual laboratory dengan setelah menggunakan Virtual laboratory dapat dilihat pada Gambar 2.

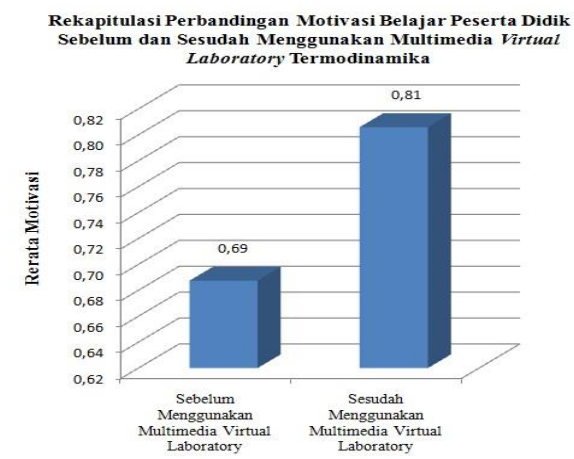

Gambar 2. Rekapitulasi Perbandingan Motivasi Belajar Peserta Didik Sebelum dan Setelah Menggunakan Virtual laboratory Termodinamika

Hasil pre-test peserta didik sebelum menggunakan Virtual laboratory diperoleh rerata 43,13dan Hasil post-test peserta didik setelah menggunakan Virtual laboratory diperoleh rerata 76,13 . Hal ini menunjukkan adanyapeningkatan 33,0\% dari nilai pre-test ke nilai post-tes, kemudian hasil analisis $\mathrm{N}$-gaindidapat:

$$
\begin{gathered}
N \text {-gain }=\frac{S_{\text {Postest }}-S_{\text {Pretest }}}{S_{\text {Maximum }}-S_{\text {Pretest }}} \\
N \text {-gain }=\frac{76,13-43,13}{100-43,13} \\
N \text {-gain }=\frac{33,00}{56,88} \\
N \text {-gain }=0,58
\end{gathered}
$$

Berdasarkan analisis hasil penelitian didapatkan hasil perhitungan $\mathrm{N}$-gain sebesar 0,58 maka termasuk dalam kategori sedang.

Rerata hasil belajar peserta didik pada pre-test belum menggunakan Virtual laboratory termodinamika dan post-test menggunakan Virtual laboratory termodinamika dapat dilihat pada Gambar3.

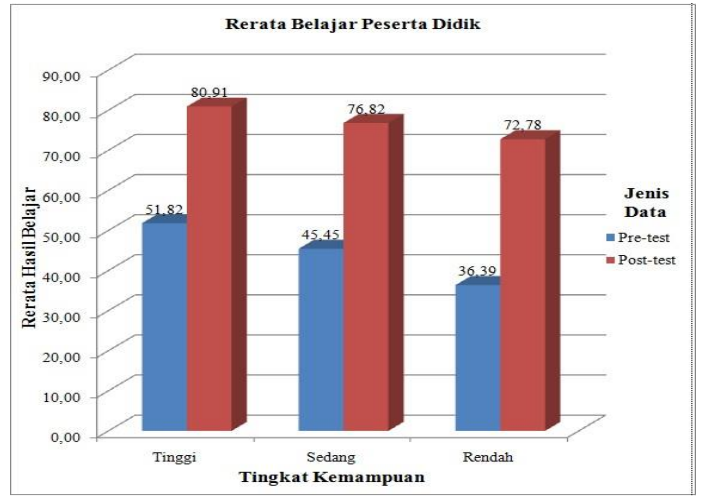

Gambar 3. Rerata Hasil Pre-test Peserta Didik dan Post-test Peserta Didik

Rekapitulasi rerata nilai pre-test dan post-test peserta didik dapat dilihat pada Gambar 4.

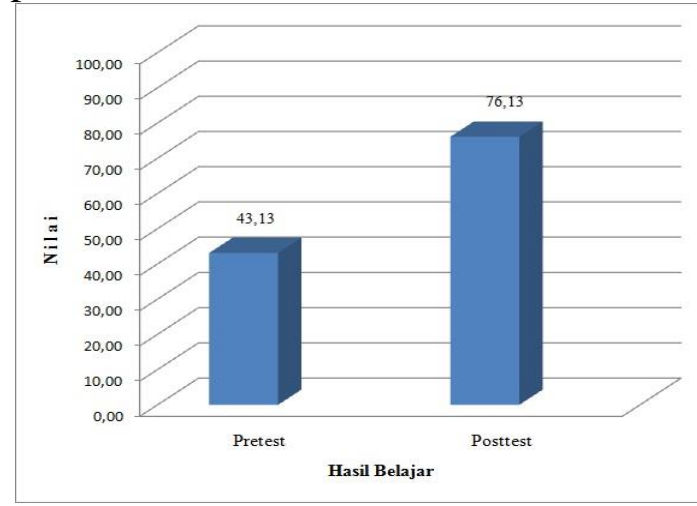

Gambar4. Rekapitulasi Perbandingan Hasil Pre-test Peserta Didik dan Post-test Peserta Didik

Rekapitulasi rerata N-Gain peserta didik dapat dilihat pada Gambar 5 berikut.

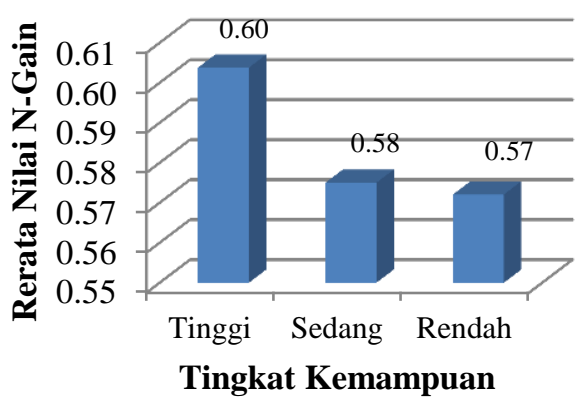

Gambar 5. Rekapitulasi Perbandingan Hasil NGainPeserta Didik 


\section{PEMBAHASAN}

Hasil penelitian menunjukkan bahwa virtual laboratory termodinamika yang dikembangkan memiliki kategori valid, praktis dan efektif digunakan dalam proses pembelajaran, hal ini dibuktikan berdasarkan pada penilaian expert review dengan rerata 4,08 kategori valid, rerata one to one evaluation sebesar 4,23 dengan kategori sangat praktis, small group evaluation sebesar 4,47 dengan kategori sangat praktis, peningkatan motivasi belajar peserta didik dari 0,69 menjadi 0,81 dengan persentase peningkatan sebesar $12 \%$ dan peningkatan pre-test dan post-test peserta didik sebesar 33,0\% dimana rerata pre-test sebesar 43,13 dan posttest sebesar 76,13.

Hasil penelitian ini selaras dengan penelitian sebelumnya yang pernah dilakukan oleh Clark, dkk (2014) yang ditulis dalam jurnal dengan penelitian terhadap mahasiswa yang memiliki kesulitan memahami konsep termodinamika dapat diketahui melalui serangkaian pertanyaan dan observasi pada saat dan sebelum pembelajaran. Kulkarni dan Tambade (2013) menghasilkan Thermodynamics Concept Test (TCT) untuk mengatasi kesulitan mahasiswa dalam memahami konsep termodinamika. Maldarelli, dkk (2009) menghasilkan video pada virtual laboratory untuk meningkatkan pengetahuan siswa dalam pembelajaran teknik laboratorium biologi dasar. Fernandez, dkk (2011) menghasilkan virtual laboratory dalam melakukan eksperimen untuk menganalisis perilaku noninverting amplifier yang dimasukkan dalam sebuah osilator dan osiloskop.

\section{SIMPULAN}

Berdasarkan hasil penelitian yang telah dilakukan di SMAN 2 Palembang tahun pelajaran 2014/2015 maka dapat disimpulkan bahwa virtual laboratorymateri termodinamika memiliki kategori valid, praktis dan efektif digunakan dalam proses pembelajaran, hal ini dibuktikan berdasarkan pada penilaian expert review dengan rerata 4,08 kategori valid, rerata one to one evaluation sebesar 4,23 dengan kategori sangat praktis, small group evaluation sebesar 4,47 dengan kategori sangat praktis, peningkatan motivasi belajar peserta didik dari 0,69 menjadi 0,81 dengan persentase peningkatan sebesar $12 \%$ dan peningkatan pre-test dan post-test peserta didik sebesar 33,0\% dimana rerata pre-test sebesar 43,13 dan posttest sebesar 76,13 kemudian hasil analisis $N$-gaindidapat sebesar 0,58 dengan kategori sedang.

\section{DAFTAR PUSTAKA}

Alessi \&Trollip. (2000). Chart of Learner Characteristics. http://www.uiowa.edu/ c07w18 0e/current/Fig13-

2_Learners.pdf. Diakses tanggal 29 November 2014.

Clark, J. W. (2014). Investigating Student Conceptual Difficulties in Thermodynamics Across MultipleDisciplines: The First Law and P-V Diagrams. Dalam American Society for Engineering Education Annual Conference and Exposition.

Suyatna, Agus, dkk. (2009). Peningkatan Aktivitas dan Hasil Belajar Fisika Siswa Melalui Pembelajaran Inkuiri. http://pustakailmiah.unila.ac.id/ wpcontent/uploads/2009/07/AgusSuyatna-dan-Dewa-Putu- 
Nyeneng- peningkatanaktivitas1.pdf. Diakses tanggal 23 Desember 2014.

Tessmer. M. (1998). Planning and Conducting Formative Evaluations. London: Kogan Page Limited.

Wiyani, N. A. (2013). Desain Pembelajaran Pendidikan: tata rancang pembelajaran menuju pencapaian kompetensi. Yogyakarta: Ar-Ruzz Media. 